\title{
LA FORMACIÓN PROFESIONAL EN LA FACULTAD DE EDUCACIÓN DE MATANZAS, CUBA, PARA PREVENIR LA VIOLENCIA
}

\author{
Hedaly Aguilar Gamboa*, Enrique Gutiérrez Espinosa**, \\ Arturo Sánchez López*** \\ *Facultad de Humanidades, Campus VI, UNACH \\ ** Facultad de Contaduría y Administración, Campus I, UNACH \\ *** Facultad de Humanidades, Campus VI, UNACH
}

\section{RESUMEN}

La prevención de la violencia escolar en las instituciones educativas requiere de docentes preparados para enfrentar esta problemática. El estudio tuvo como propósito analizar las acciones incorporadas en la formación de los estudiantes de la Facultad de Educación de Matanzas, Cuba, y la percepción que tienen sobre cómo prevenir situaciones de violencia escolar para aplicarlas en su desempeño profesional. Con enfoque cuanti-cualititativo con un diseño de corte explicativo secuencial para identificar las actividades que realizan, orientadas al proceso formativo de los estudiantes sobre la prevención de la violencia escolar para su desempeño profesional, conocer la opinión de los docentes, respecto del proceso formativo de los estudiantes sobre la prevención de la violencia escolar para su desempeño profesional, conocer la percepción que tienen los estudiantes de su proceso formativo que les permita en su desempeño profesional prevenir situaciones de violencia escolar y conocer cómo participan los docentes, directivos y estudiantes en los programas y proyectos para la prevención de la violencia

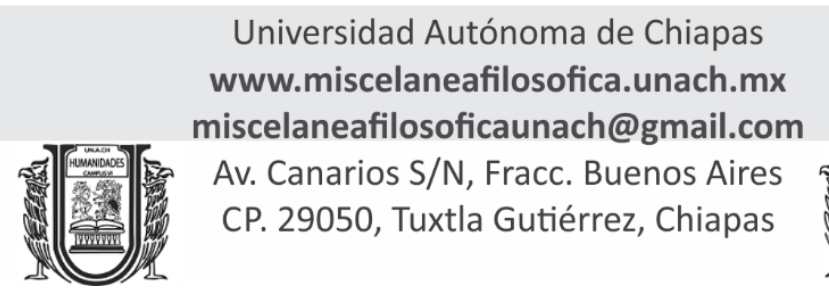


